\title{
Real Time Simulation of HVDC and VSC-HVDC models: Application to Algerian - Spanish Power System Interconnection
}

\author{
M.Khiat ${ }^{1}$ and L. Ghomri ${ }^{1}$ \\ ${ }^{1} \mathrm{ENPO} / \mathrm{SCAMRE}$ \\ BP EL M'Naouer-Oran-Algeria \\ Phone/Fax number:+0034 986 812685, e-mail: Mounir.khiat@enp-oran.dz, lilaghomri@yahoo.fr
}

\begin{abstract}
Most of world's electric power systems are now widely interconnected involving inter-regional and international connections. The purpose is to achieve better efficiency in generation and transmission of energy. We need these interconnections to take advantage of diversity of loads, availability of sources and fuel price to supply electricity at minimum cost with a required reliability.

In addition to the existing interconnections, namely those of the Maghreb, Algeria is Already interconnected to Tunisia (4 connections) and to Morocco (2 connections).

But a direct interconnection with European countries around Mediterranean Sea will be open up new opportunities to both partners for economic and technical reasons. Since 2002, Algeria has a new politic to diversify international exchanges.

A great number of studies of Interconnection Algerian-Spanish network project have been done by many organisations. Furthermore with the HVDC and VSC-HVDC technology, who allowed DC transport, this interconnection, can be achieved with high reliability.

But there is the constraint that Maghreb countries networks are weak in comparison with Spanish one which is robust, and strongly interconnected with European network. In order to give some elements of solution to realise this project, real time simulators of grids are an interesting tool. These simulators are used to simulate grids and electrical equipments with input/output signals to interact with real equipment.

In this article, we present different HVDC and VSC-HVDC models, and we will define the best adaptive one to real time simulation, and results obtained with EMEGASIM of the RTLAB platform.
\end{abstract}

\section{Key words}

Power systems interconnection; HVDC and VSC-HVDC models; Algerian-Spanish interconnection; real time simulation; RT-LAB platform.

\section{Introduction}

Together with the important expansion of industry and technology in the entire world, the demand in energy increase very quickly. The construction of new transmission lines and new stations of productions is sometimes difficult and the cost is high . The majority of electrical networks are actually widely interconnected: internal interconnections, regional and international.

In recent years, the SEMCs undertook to interconnect their power networks in order to further develop electricity exchanges.

In addition to the existing interconnections, namely those of the Maghreb, Algeria is already interconnected to Tunisia (4 connections) and to Morocco (2 connections),

Recent connections were brought into service, including those linking Spain to Morocco, Libya to Egypt, Egypt to Jordan, and Syria to Jordan and Lebanon.

Several new interconnection projects are under way linking Morocco to Algeria (third connection), Algeria to Tunisia (fifth connection), Tunisia to Libya, Libya to Egypt, Syria to Turkey, and Turkey to Greece. Concerning the interconnections presently planned at 220 $\mathrm{kV}$, their voltage is planned to be increased to $400 \mathrm{kV}$ at a later stage.

The new projects will enable major SEMCs to interconnect as well as to connect with the European network following the completion of the "electrical loop" around the Mediterranean in 2005. OME participated to the «MedRing»1 study related to the behaviour of the "Mediterranean electrical loop" which is supported by the European Commission. The Med Ring project (26 months study) is completed in May 2003. 
THE MEDITERRANEAN ELECTRICAL RING

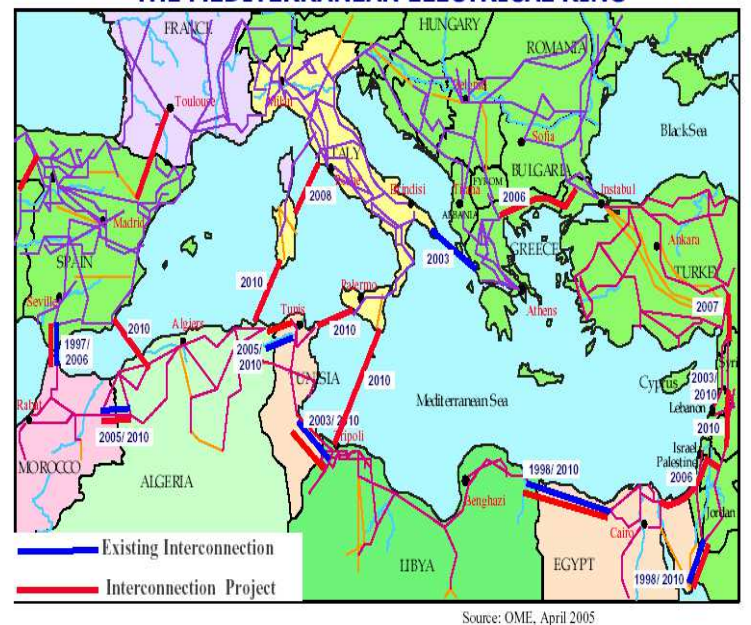

Figure.1. Euro-Mediterranean interconnections

Thanks to the completion of "the Mediterranean electrical loop", an increase in Mediterranean electricity exchanges is expected by 2010. According to the estimations of the Med Ring study, power exchange will increase from the 60 TWh in 2003 to 75 TWh by 2010 .

In this context, we offer our contribution in this article, to the project: Algerian-Spanish power system interconnection.

One of the most interesting advantages of a direct link between the two countries is that units of production in Algeria will be elements of the European electrical system, and offer by this fact some advantages:

-Delocalisation of productions stations: no need to built new units in Europe.

-Because of growing the quantity of energy flow, it permitted a better security of providing.

-High probability to calling European technology, for project realisation.

Following to the accord protocol concluded between Algerian minister of energy and its Spanish homologue, in one part, and REE (Red Electrica de Espana) and SONELGAZ (Algerian society) a feasibility study has been done for an electrical interconnection of $2000 \mathrm{MW}$ : 1000MW for Algerian part and 1000MW in freeware.

This interconnection will be achieved by sub-marine cables which relies the west Algerian and south of Spain. The first part of this study has been achieved in July 2002, and the second part in December 2002.

The geographic proximity of Spain makes this country an ideal partner for a submarine link.

The question is: what is the most economical and suitable way to achieve this interconnection: two alternatives are possible: in $\mathrm{AC}$ or in $\mathrm{DC}$.

In this paper, we will compare the two technologies $\mathrm{AC}$ and DC, in next chapter, and then we will present the HVDC and VSC- HVDC technology developed by ABB Group (HVDC light) and Siemens group (HVDC plus), and finally we will propose an Algerian-Spanish interconnection with HVDC or VSC- HVDC.

\section{HVDC transmission principle}

HVDC stands for High Voltage Direct Current and is today a well-proven technology employed for power transmission all over the world. In total about 70,000 MW HVDC transmission capacities is installed in more than 90 projects. ABB has supplied the converter stations in more than 47 of these projects with a total transmission capacity of about $\quad 40,000 \mathrm{MW}$. There are three different categories of HVDC transmissions [4].

\subsection{Point to point transmission}

Most HVDC transmissions are point to point transmissions using overhead lines or submarine cables or a combination of lines and cables. Two configurations are possible: Monopolar and bipolar HVDC transmissions.

Many of the cable transmissions are monopolar with only one metallic conductor between the converter stations and using the ground as the return path for the current.

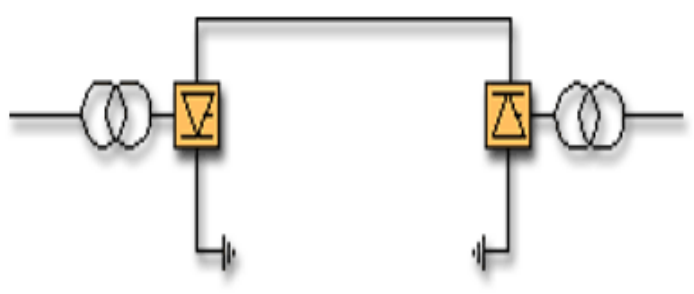

Figure. 2. Monopolar configuration

Most overhead line transmissions are bipolar, i.e. they use two conductors of opposite polarity (one positive and one negative). A bipolar transmission is in fact a double circuit transmission, since one pole can continue to transmit power when the other pole is out of service.

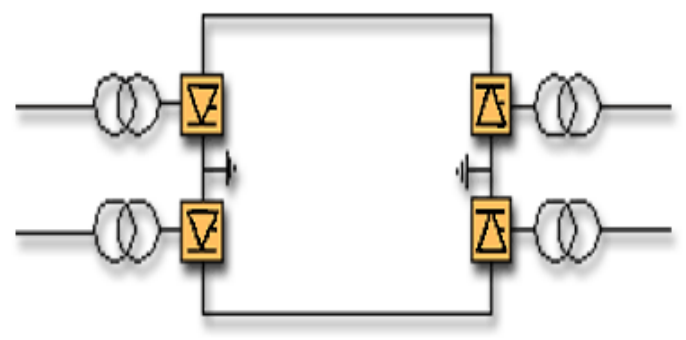

Figure.3. Bipolar configuration

Where it is essential to have at least $50 \%$ power if an outage occurs and for large size transmissions, a bipolar HVDC transmission is the natural choice. For network interconnections of moderate size often a monopolar configuration

is

chosen. 
Bipolar HVDC converter stations are designed such that there shall be no risk of having a forced outage of both poles at the same time. The most probable type of line fault: a ground fault due to lightning, affects only one pole. Bipolar HVDC line faults only happen in case of a fallen line tower. Since bipolar faults are very rare, one can regard a HVDC bipole as being equivalent to a double circuit $\mathrm{AC}$ line from the reliability point of view.

\subsection{HVDC back-to-back transmission}

HVDC back-to-back station is normally used to create an asynchronous interconnection between two AC networks.

There are several back-to-back stations in operation in the world. In these installations both the rectifier and the inverter are located in the same station and are normally used in order to create an asynchronous interconnection between two AC networks, which could have the same or different frequencies.

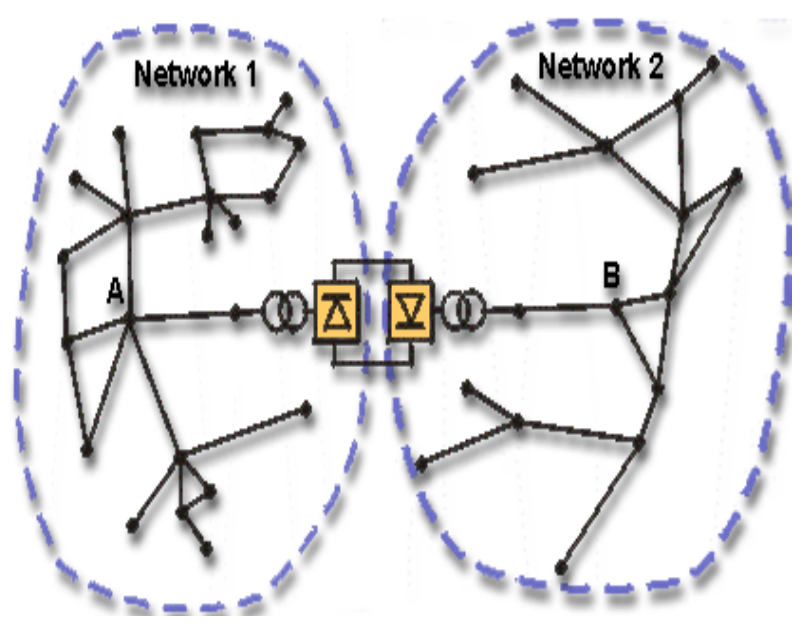

Figure .4. Back-to-Back transmission

\begin{abstract}
A back-to-back station is normally somewhat simpler than a converter station for a transmission project. The direct voltage level can be selected without consideration to the optimum values for an overhead line and a cable, and is therefore normally quite low, $150 \mathrm{kV}$ or lower. The only major equipment on the DC-side is a smoothing reactor. The control equipment can also be simplified, as there is no need for a telecommunication link between the two converters.
\end{abstract}

\subsection{Multiterminal systems}

A multi-terminal HVDC transmission is an HVDC system with more than two converter stations.

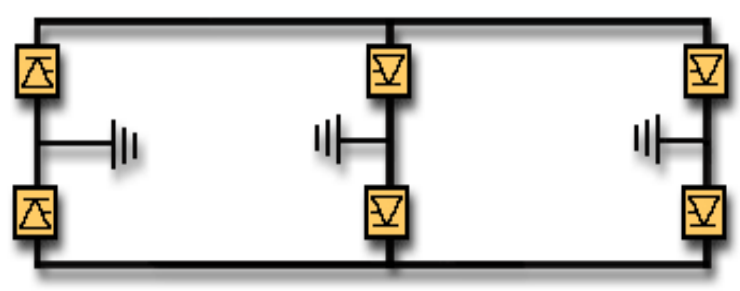

Figure. 5. Multi-terminal HVDC transmission

A multi-terminal HVDC transmission is more complex than an ordinary point-to-point transmission. In particular, the control system is more elaborate and the telecommunication requirements between the stations become

larger.

There is only one large-scale multi-terminal HVDC system in operation in the world today. It is the 2,000 MW Hydro-Quebec-New England transmission built by ABB between 1987 and 1992.

Technology came around 1970 when thyristor valves were introduced in place of the mercury arc valves. This reduced the size and complexity of HVDC converter stations substantially. The use of microcomputers in the control equipment in today's transmissions has also contributed to making HVDC the powerful alternative in power transmission that it is today.

\subsection{Converter station design principles}

One of the main objectives during the design of a HVDC converter station is to minimize the outage frequency and outage time due to both forced and scheduled outages. This can be achieved by:

- Simple and well proven station design

- Use of reliable and well-known components

- Automatic monitoring of all critical subsystems

- Use of redundancy

\section{VSC-HVDC}

VSC- HVDC (HVDC light or HVDC plus) is the successful and environmentally-friendly way to design a power transmission system for a submarine cable, an underground cable or back-to-back transmission.

One HVDC unit is capable of transmitting more than $350 \mathrm{MW}$, with a voltage up to $150 \mathrm{kV}$. Note that VSCHVDC is HVDC technology based on voltage source converters (VSCs). Back-to-back or combined with extruded DC cables, power ratings from a few tens of megawatts up to several hundreds of megawatts are available. VSC-HVDC converters include insulated gate bipolar transistors (IGBTs) and operate with high frequency pulse width modulation in order to achieve high speed and as a consequence small filters and independent control of both active and reactive power. These types of converters are able to switch off the DC current independent of the AC voltage. Furthermore, the VSC inverter can create its own AC voltage in case off a black AC network, through high frequency switching between the +/- DC voltage.

We can finally summarise SVC- HVDC principle advantages in the following points: 
- VSC converter can create its own AC frequency with the PMW technique.

- Communication between the two stations is not necessary.

- A suitable control permits to eliminate flickers problems.

- HVDC stations can be used as STATCOM for local network.

- Materiel have more long lifetime than classical HVDC one.

- In environmental point of view, stations are compacts; no visual impact.

\subsection{VSC- HVDC modules}

Conversion bridges (rectifier and inverter) consist of three phases, with two IGBT valves per phase. The corresponding AC phase is connected between the two valves, which enables the three phases to create a symmetrical DC voltage with opposite polarities. (Figure 6).

We obtain in the output a continue voltage with a frequency of IGBT commutation of $2 \mathrm{KHz}$.

In continue part, are installed a battery of condensers in order to stabilize the voltage. The capacitors stacks are being charged to opposite polarities by the high frequency switching IGBT's.

In the AC part, filters are necessary for avoiding IGBT commutation harmonics.

VSC- HVDC converters stations have a good visual impact, the converter stations are enclosed in a building, makes the impact of the transmission system on the environment very low. The building can be designed to resemble other buildings in the Neighbourhood and the cables are not even visible.

To avoid high steel support structures, to facilitate maintenance and to improve personal safety, the AC filters, converter reactors and DC filters are mounted directly on low foundations/supports and are kept within a simple warehouse-style building with lockable gates and doors. The building will keep high-frequency emissions and acoustic noise low and protect the equipment from adverse weather.

\section{Algerian-Spanish interconnection}

The aim of the proposed collaboration is to study Spanish and Maghreben countries (especially Algeria and Morocco) electrical systems interconnection via Gibraltar Detroit. Morocco part: $1400 \mathrm{MW}$ in $400 \mathrm{KV}$, and Algerian part: (2000MW, 400KV). We must take in account in this interconnection that the Spanish electrical network is very strong and robust and highly interconnected with the European one, when the Algerian one is characterized by: -Many loads buses radially connected to the main grid.

-Certain consumption areas remotely located from injection buses.

-Uneven distribution of reactive power reserves among available generators.

-Insufficient number of shunt reactor.
For these reasons, a classical AC interconnection will have disastrous repercussions on Algerian network in case of incidents in the Spanish one.

Actually, Spain has a slow progression of production capacities in regard of the economic expansion and in result, perturbations in electricity distribution especially in the south. A study has affirmed that the needs are in less $4000 \mathrm{MW}$ for avoiding this problem. This demand is unrealisable in the middle term, because the price of gas has been doubled, and Spain is a gas export country.

Add to that an interconnection is generally more benefit than constructing new power electrical stations for economic and environmental reasons.

\subsection{Technical view}

The 2000MW project already mentioned below is in the realisation phase, by DC. Algeria, via its national society "SONELGAZ", would a competitive operator in the Mediterranean ring by developing Euro- Maghreb axes of transit. For these reasons, the "2000MW project" has been initied in the idea of the development of $400 \mathrm{KV}$ by transport network.

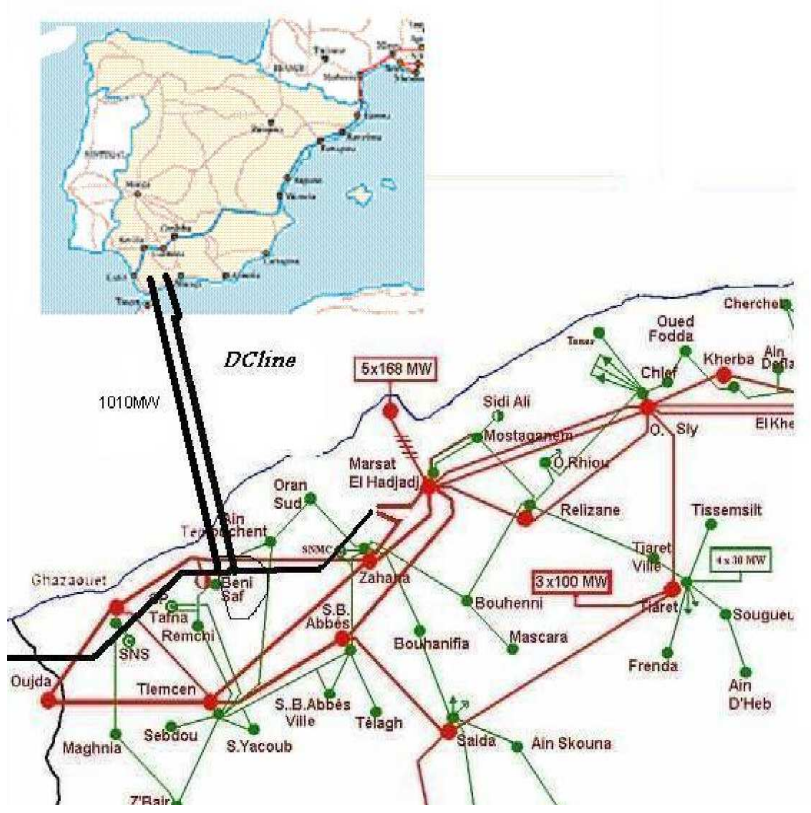

Figure.6. Algerian- Spanich Sub-marine link

The aim is the conception, the construction, and the exploitation of one or many electrical stations which totalise a power of $2000 \mathrm{MW}$, and the commercialisation of this energy. For local needs: $800 \mathrm{MW}$, and 1200MW for exportation.

\section{Real Time Simulation of HVDC and VSC-HVDC models}

But there is the constraint that Maghreb countries networks are weak in comparison with Spanish one which is robust, and strongly interconnected with European network. In order to give some elements of solution to realise this project, real time networks simulators are an interesting tool. These simulators are 
used to simulate networks and electrical equipments with input/output signals to interact with real equipment.

\subsection{Hardware architecture}

Figure.7. shows the simulator architecture installed within our laboratory SCAMRE. Is composed for two simulators connected, the Wanda $4 \mathrm{u}$ (figure .8.) and the OP 5600 (figure .9.). The target is equipped with two CPU processers (Intel Xenon six-core, 3.33 GHZ, $12 \mathrm{M}, 6.4$ $\mathrm{GT} / \mathrm{s}$ ), for Wanda and two CPU processers (Intel Xenon six-core, $3.46 \mathrm{GHZ}, 12 \mathrm{M}, 6.4 \mathrm{GT} / \mathrm{s}$ ) for OP5600. The target is responsible for execution of models. Development, edit, verification, and compilation of models are all done on the host computer; moreover, it works as a console or command station in charge of control and observation during simulation. Ethernet is used to communicate between hosts and targets. Communication among nodes is used shared-memory architecture. The host computer is a general PC.

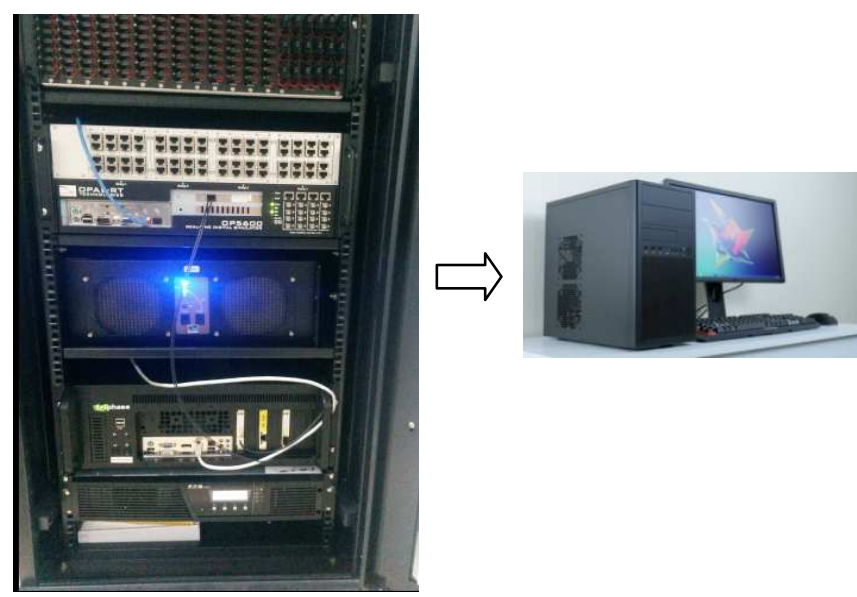

Figure.7. RT-LAB Simulator Architecture

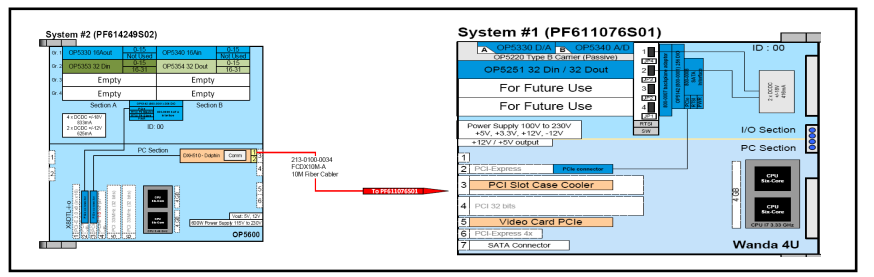

Figure.8. System Hardware Overview for op5600 and Wanda 4u

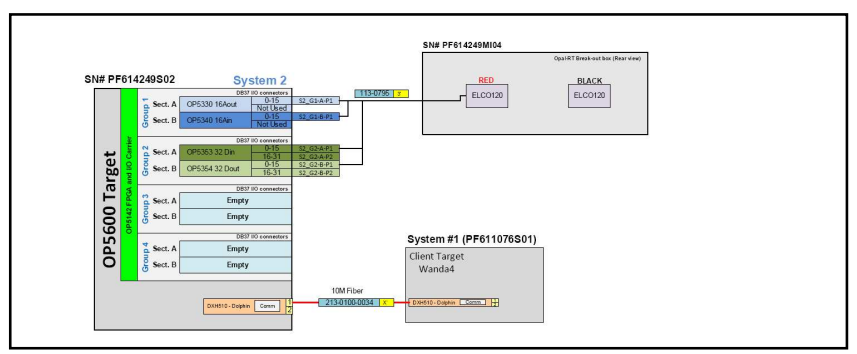

Figure.9. System Connection Overview

\subsection{Software architecture}

Figure.10. is the software architecture on the host. All studied models are developed under the Matlab/Simulink environment. RT-LAB is a real-time GUI platform and designed to make the real-time simulation of the Simulink models on the clusters. RT-LAB builds parallel tasks from the original Simulink models and run them on each core of the multi-core CPU computer or on the separate computers [16].

In the RT-LAB simulation platform, a solver named Artemis (is a fixed time-step size solvers) which is designed specifically for power system can improve the simulation speed greatly, and the multi-processor operating mode makes it available to do real-time simulations on RT-LAB platform by separating a complex system to some simple subsystems and do parallel operations in multiprocessor. RT-LAB can also connect physical devices to the simulation system to make the simulation closer to the reality and get more convincing results.

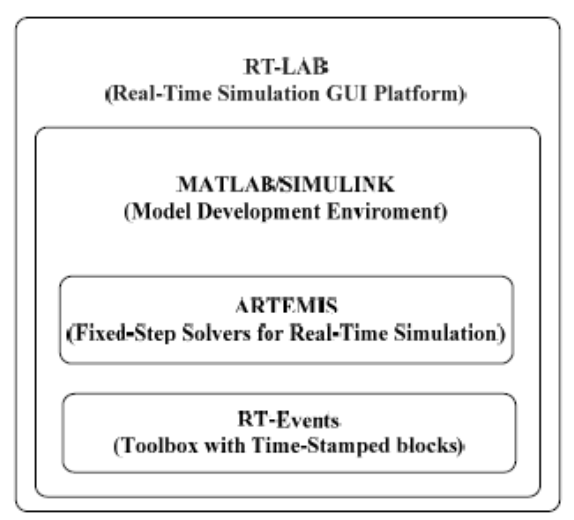

Figure.10. Software Architecture [16]

\subsection{Modelling and simulation of HVDC and VSC- HVDC}

Before finalizing the project, it is interesting to realise a models of interconnection by HVDC and VSC-HVDC and to simulate it in real time. It will allow us to have some interesting conclusions about this connection between the Algerian and Spanish systems.

In order to simulate HVDC and VSC-HVDC models in real time with the Opal-RT software, first of all the entire model has to be rearranged mainly into three subsystems, which are master, slave and console subsystems. 


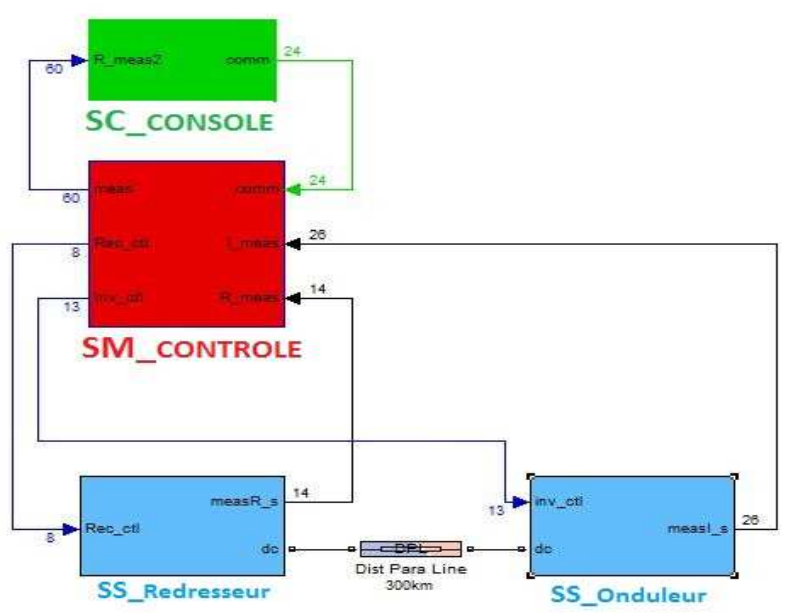

Figure.7. Example HVDC model dedicated to the real-time simulation.

The studied systems are modeled in an environment that integrates Simulink/SimPowerSystems with the eMEGAsim simulation of the RT LAB platform, which incorporates $[14,15]$. This platform enables the simulation of increasingly large systems with real-time performance across multiple CPUs. Through the use of the TestDrive graphical user interface platform from OPAL-RT Technologies, it is also demonstrated that observing results and modifying parameters and conditions on a real-time simulated model is both easy and user friendly [15].

We will present in next step different of VSC-HVDC models, and we will define the best adaptive one to real time simulation, and results obtained with eMEGAsim of the RT-LAB platform.

The results with the graphs of the real-time simulation of HVDC and VSC-HVDC models and their interpretations will be later presented in a second part of the article.

\section{Conclusion}

The interconnection of Algerian network and the European one via Spain is one of the most important realisations in energy sector for the two countries. The benefits are considerable VSC- HVDC is a new technology. The power transmitted until now is not sufficient for assuming the interconnection, but, the progress of research for more power encourages us to be optimists.

We can resume the benefit of this type of interconnection especially in emergency cases, in the following point: VSC- HVDC transmission system will be a very valuable asset during a grid restoration. It will be available almost instantly after the blackout and does not need any short circuit capacity in order to become connected to the grid.

\section{References}

[1] M. Bahrman, "HVDC Transmission, An Economical Complement To AC Transmission", PE, ABB Grid Systems, WECC Transmission Planning Seminar, February 2-3, 2009.

[2] R. Rudervall, J.P. Charpentier, R. Sharma, " High Voltage Direct Curre (HVDC)Transmission Systems Technology Review Paper ", Presented at Energy Week 2000, Washington, D.C, USA, March 7-8, 2000.
[3] C.K. Kim., V.K. Sood., G.S. Jang., "HVDC Transmission, Power Conversion Applications in Power Systems. ", IEEE Press., John Wiley \& Sons (Asia) Pte Ltd., 2009.

[4] J. Arrilaga, Y.H. Liu, N.R Watson, " Flexible Power Transmission, The HVDC Options. ", John Wiley \& Sons., 2007 [5] D. OCNASU, “ Modélisation, Commande et Simulation Temps Réel Hybrides Des Systèmes De Génération Non Conventionnels ", Thèse Doctorat, Université Joseph, Fourier, Octobre 2008.

[6] G.Benstaam, L.Carlsson," HVDC light, grid friendly and ecological technology" ABB review.

[7] Habib El Andaloussi "La boucle électrique méditerranéenne" $1^{\text {ère }}$ conférence internationale sur le transport de l'électricité en Algérie. Septembre 2005.

[8] Lidong Zhang, Lars Dofnas (ABB Utilities Power System Technology), "A Novel Method to Mitigate Commutation Failures in HVDC Systems," Proceedings PowerCon 2002, Volume: 1 , pp 51-56, 13-17 Oct. 2002,

[9] Xiao-Ping Zhang, Christian Rehtanz, Bikash Pal, «Flexible AC Transmission systems : Modelling and Control», Springer 2005.

[10] Z. Xiongguang, "Control of Multi-Terminal VSC-HVDC System to Integrate Large Offshore Wind Farms" IJCEE, Vol. 5. 2013.

[11] J. Bjorn, "VSC-HVDC Transmission with Cascade TwoLevel Converters ". Paris : CIGRE, 2010.

[12] Dorn, J. "A new Multilevel Voltage-Sourced Converter Topology for HVDC Applications". Paris : CIGRE, 2008.

[13] G. Minyuan, "Modeling and Control of a Modular Multilevel Converter Based HVDC System Under Unbalanced Grid Conditions". IEEE transactions on power electronics, Vol. 27. 2012.

[14] User's Guide, “ SimPowerSystems R2013a ”, HydroQuébec and The MathWorks, Inc., 2013.

[15] User's Guide, "Real-Time Workshop 7 ", by The MathWorks, Inc., 2010.

[16] H. C. Su, G. W. Chang, H. M. Huang K. K. Jen, G. C. Chun, and G. Z. Wu, "Analysis of Wind Generation System by Real-Time Simulation "National Chung Cheng University Chia-Yi, Taiwan 2012. 